\title{
Matching Assessment of the Chassis and Fire System of Wheeled Vehicle Mounted Gun Based on the Index $(0,2)$ Scale
}

\author{
Liu Chuan $^{1, a}$, Xue Deqing ${ }^{1}$ and Jia Changzhi ${ }^{1}$ \\ ${ }^{1}$ Department of Guns Engineering, Ordnance Engineering College, Shijiazhuang, 050003 \\ ${ }^{a}$ Corresponding author
}

\begin{abstract}
The matching problem of the cannon and vehicle has been studied a lot, but the studies are more about the self-propelled guns with armored chassis, studies of the truck-mounted artillery with truck chassis are less now. AHP method is used in this paper and the vehicle chassis and artillery fire system matching evaluation factors are listed in this paper, the evaluation system is been established and a evaluation model is built in the end. Aiming at the disadvantages of the traditional AHP method in the proportion of 1-9 scaling, the $(0,2)$ index scale is used in this paper, the judgment matrix which meets the consistency requirements is built and the subjective of the judgment matrix is reduced.
\end{abstract}

\section{Introduction}

The matching of the chassis system and fire system means the reasonable degree and consistency of the chassis system and fire system of the associativity in structure and performance, Included in the thermal reliability, flexibility, such as mechanical strength performance and the overall performance of the composite system to achieve the optimal. Now, some internal scholars, like Mao Baoquan and $\mathrm{Mu} \mathrm{Ge}[1,2]$ have did some studies for self-propelled guns with armored chassis, but the study of the truck-mounted artillery with truck chassis is less now. This paper mainly aims at the matching problem of the chassis system and fire system of Vehicular artillery, lists the evaluation factors and establishes the evaluation system and evaluation model. Wish to provide certain reference for the matching of the chassis system and fire system of Vehicular artillery.

\section{Evaluation factors and evaluation system}

\subsection{Evaluation factors}

Vehicular artillery is different with self-propelled guns, the truck chassis needs to be considered more when choosing the evaluation factors.

By analysing and researching the combat and load characteristics of the vehicular artillery platform, the main factors which impact the platform's mechanical properties and mechanical properties is confirmed. By asking experts and actual measurement, the main evaluation factors are listed in the following Table 1:

Table 1. Main evaluation factors

\begin{tabular}{|c|c|c|}
\hline $\begin{array}{c}\text { evaluation } \\
\text { indices }\end{array}$ & Structure match & performance match \\
\hline \multirow{10}{*}{$\begin{array}{c}\text { evaluation } \\
\text { factors }\end{array}$} & Length of vehicle & Vehicle body angle of maximum amplitude \\
\hline & Length-width ratio of vehicle & $\begin{array}{l}\text { Vehicle body vertical (horizontal) to the angular } \\
\text { displacement }\end{array}$ \\
\hline & Height of chassis & Ratio of vehicle and cannon \\
\hline & Barycentric position of the chassis & Height of the fire line \\
\hline & Chassis seat minimum area & March battle conversion time \\
\hline & Seat position & Firing rate \\
\hline & Shape of seat & $\begin{array}{l}\text { The vertical (horizontal) to the angular displacement } \\
\text { of the muzzle }\end{array}$ \\
\hline & The limit of Combat weight & $\begin{array}{l}\text { The vertical (horizontal) to the angular velocity of the } \\
\text { muzzle velocity }\end{array}$ \\
\hline & The hoe connected position & $\begin{array}{l}\text { The vertical (horizontal) to the angular acceleration of } \\
\text { the muzzle }\end{array}$ \\
\hline & Limit took long & Battle-sight range \\
\hline
\end{tabular}




\subsection{The establishment of evaluation system}

Combining with evaluation index and the main evaluation factors and using the AHP method, the evaluation system is divided into target layer, criterion layer and layer solution.

\section{The method of $(0,2)$ index scale}

Analytic hierarchy process, referred to as 'AHP', is a kind of multi-objective multi-criteria decision-making method.

So-called index scale method[3] is the two factors of group compared to the importance of the $C_{i}$ and $C_{j}$ are divided into several levels, as $C_{i j}=1,2, \ldots$ With the introduction of two adjacent level objective importance ratio $a(a>1)$, so the objective importance ratio of $C_{i}$ and $C_{j}$ is $a^{c_{i j}}=W_{i} / W_{j}$, where $W_{i}$ and $W_{j}$ represent the objective importance of $i$ and $j$ respectively, $C=\left(C_{i j}\right)_{n \times n}$ and $B=\left(a^{b_{i j}}\right)_{n \times n}$, respectively called subjective feeling matrix and objective difference judgment matrix. Then using the logarithm least squares method in matrix $B$, and get the vector $\bar{\omega}$ containing parameter $a$ by using the row sum of the matrix $C$, the weight vectors can be got after determining and normalizing the value of $a$. Where, $b_{i j}=r_{i}-r_{j}$.

Many methods can be used to confirm the value of $a$ : Through designing the questionnaire $a$ is equal to 1.361. According to the "ladder by leaps" principle, the literature [4] get $a$ is equal to 1.618. While the literature [5] shows that to the parameter $a(a>1)$, if any disturbance $\Delta a$ meet the condition that $a+\Delta a>1$, the ranking result before and after the disturbance will not

\subsection{Hierarchy total sorts}

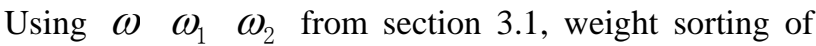

change. So whether the value of $a$ is equal to 1.361 or 1.618, might change is the finally weight of each index, but the finally sorted result will not change. In this paper $a$ is equal to 1.361 .

\section{The establishment of the evaluation model}

\subsection{Hierarchical single sort}

First, establish the subjective feeling matrix $C$ which the criterion layer to the target layer, through expert scoring method, using $(0,2)$ index scale to establish the subjective feeling matrix and the rank of the importance of each element is as follows:

Subjective feeling matrix $C$ and its row sum $r_{i}$ :

$C=\left[\begin{array}{ll}1 & 0 \\ 2 & 1\end{array}\right] \quad r_{i}=\left(\begin{array}{ll}1 & 3\end{array}\right)$

Objective importance ratio $a$ is equal to 1.361 and then get the objective difference judgment matrix $B$ :

$B=\left[\begin{array}{ll}1.361^{0} & 1.361^{-2} \\ 1.361^{2} & 1.361^{0}\end{array}\right]=\left[\begin{array}{cc}1 & 0.5399 \\ 1.8523 & 1\end{array}\right]$ Using the logarithmic least squares method to find the parameters of the vector $a$ :

$$
\bar{\omega}=\left(a^{\left(\sum_{j=1}^{n} b_{1 j}\right) / n}, a^{\left(\sum_{j=1}^{n} b_{2 j}\right) / n}, \ldots, a^{\left(\sum_{j=1}^{n} b_{n j}\right) / n}\right)
$$

Let $a$ equals 1.361: $\bar{\omega}=\left(1.361^{-1}, 1.361^{1}\right)$

Weight sorting after normalized $\omega=(0.35,0.65)$

Using the samie method, the effect weight of each factor under $B_{1} B_{2}$ can be calculated:

$\omega_{1}=(0.0021,0.0076,0.0261,0.3072,0.0141,0.5688,0.0041,0.0076,0.0483,0.0141)$

$\omega_{2}=(0.0211,0.0114,0.0392,0.0726,0.0062,0.0018,0.4611,0.2489,0.1344,0.0033)$

each element of index layer to the target layer can be calculated, the result is listed in the following Table2:

Table 2. Weight

\begin{tabular}{|c|c|c|c|c|c|c|c|c|c|c|}
\hline$i j$ & 11 & 12 & 13 & 14 & 15 & 16 & 17 & 18 & 19 & 110 \\
\hline weight & 0.00073 & 0.00266 & 0.00914 & 0.10752 & 0.00494 & 0.19908 & 0.00144 & 0.00266 & 0.01691 & 0.00494 \\
\hline$i j$ & 21 & 22 & 23 & 24 & 25 & 26 & 27 & 28 & 29 & 210 \\
\hline weight & 0.0137 & 0.00741 & 0.02548 & 0.04719 & 0.00403 & 0.00117 & 0.29972 & 0.16179 & 0.08735 & 0.00214 \\
\hline
\end{tabular}

We can see that barycentric position of the chassis, seat position and the vertical (horizontal) to the angular displacement of the muzzle have great influence to the target layer. While the length of vehicle and the firing rate have less affect to the target layer. 


\subsection{The establishment of the evaluation model}

Evaluation models are for some factors which cannot direct quantitative or the non-quantitative factors, on the basis of past experience the experience model is set up, by using the evaluation models we can do quantitative evaluation to the non-quantitative factors. The commonly used evaluation models have maximum model, minimum model, normal distribution model, two sides model, middle model.

The evaluation models of each evaluation index are as follows:

Table 3. Evaluation models of each evaluation index

\begin{tabular}{|c|c|c|c|}
\hline evaluation index & evaluation model & evaluation index & evaluation model \\
\hline Length of vehicle & middle model & $\begin{array}{l}\text { Vehicle body angle of } \\
\text { maximum amplitude }\end{array}$ & minimum model \\
\hline $\begin{array}{l}\text { Length-width ratio of } \\
\text { vehicle }\end{array}$ & middle model & $\begin{array}{c}\text { Vehicle body vertical } \\
\text { (horizontal) to the angular } \\
\text { displacement }\end{array}$ & minimum model \\
\hline Height of chassis & minimum model & Ratio of vehicle and cannon & middle model \\
\hline $\begin{array}{c}\text { Barycentric position of } \\
\text { the chassis }\end{array}$ & middle model & Height of the fire line & middle model \\
\hline $\begin{array}{c}\text { Chassis seat minimum } \\
\text { area }\end{array}$ & maximum model & March battle conversion time & minimum model \\
\hline Seat position & middle model & Firing rate & maximum model \\
\hline Shape of seat & $\begin{array}{l}\text { normal distribution } \\
\text { model }\end{array}$ & $\begin{array}{c}\text { The vertical (horizontal) to the } \\
\text { angular displacement of the } \\
\text { muzzle }\end{array}$ & minimum model \\
\hline $\begin{array}{c}\text { The limit of Combat } \\
\text { weight }\end{array}$ & minimum model & $\begin{array}{l}\text { The vertical (horizontal) to the } \\
\text { angular velocity of the muzzle } \\
\text { velocity }\end{array}$ & minimum model \\
\hline $\begin{array}{l}\text { The hoe connected } \\
\text { position }\end{array}$ & $\begin{array}{l}\text { normal distribution } \\
\text { model }\end{array}$ & $\begin{array}{c}\text { The vertical (horizontal) to the } \\
\text { angular accelerationof the } \\
\text { muzzle }\end{array}$ & minimum model \\
\hline Limit took long & maximum model & Battle-sightrange & maximum model \\
\hline
\end{tabular}

\section{Conclusion}

In the past in the application of layer analysis method to solve practical problems, it is often caused deviation when building the judgment matrix due to our subjective consciousness. The method of $(0,2)$ index scale is used in this paper, our subjective consciousness when building the judgment matrix is reduced, simple and good flexibility. The vehicle chassis and artillery fire system matching evaluation factors are listed in this paper, the evaluation system is been established and a evaluation model is built in the end.

\section{Acknowledgements}

The paper is sponsors by the National Natural Science Foundation of China(item number:51175508).

\section{References}

[1] Mao Baoquan, Mu Ge. Analysis of Technology of Gun and Vehicle Matching. Journal of Gun Launch and Control. 3, 58, (2000)

[2] Wu Dongya, Mao Baoquan, et al. Research on the Method of Matching Evaluation of Armored Chassis and Gun. Journal of Gun Launch and Control. 4, 11, (2004)

[3] $\mathrm{Xu}$ Zeshui. $(0,2)$ Index Scale Method for Constructing Judgment Matrix Used in AHP Method. Journal of Qufu Normal University. 2, 48 (1999)

[4] Xu Yongfeng. Study on the Importance of Index Scale. Journal of Basic Science of Textile University. 2, 138, (2003)

[5] Liu Shuxin, Qiu Wanhua, Zhang Ruiqing. The AHP Index Scale Method. System Engineering Theory and Practice. 10, 78, (1995) 